Journal Home Page:

http://perlinguam.journals.ac.za

\section{Per ${ }_{\text {Linguam }}$}

A Journal for Language Learning Tydskrif vir Taalaanleer

\title{
INTERMEDIATE PHASE MATHEMATICS TEACHERS' PROFICIENCY IN THE LANGUAGE OF LEARNING AND TEACHING: THE EASTERN CAPE PROVINCE
}

Lindiwe Tshuma, University of the Witwatersrand

Michael Le Cordeur, Stellenbosch University

\begin{abstract}
The South African Language in Education Policy (LiEP) stipulates the use of English or Afrikaans as a language of instruction in the upper primary school, after mother-tongue instruction in the lower primary school. Educational research confirms that English is used as the official Language of Learning and Teaching (LoLT) by $90 \%$ of the learners in public schools in the country. These learners are multilingual, thus, they are also English Language Learners (ELLs). The aim of the article is to analyse the Eastern Cape Department of Education (ECDoE) Intermediate Phase (IP) mathematics teachers' language proficiency in English, the prescribed LoLT. This article is generally informed by Cummins's work and particularly informed by the socio--psycho-linguistics theory. A standardised teacher English language proficiency assessment piloted in five South African universities was administered on 55 Intermediate Phase (IP) mathematics teachers purposefully selected from 16 education districts in the ECDoE. Data were quantitatively and qualitatively analysed. Results show that teachers' language ability in English, is very low and the IP teachers who are not proficient in the language of instruction are likely to compromise the quality of mathematics instruction. Since study participants are qualified practicing teachers, this article concludes that the onus is on teacher education institutions to linguistically prepare IP mathematics teachers adequately.
\end{abstract}

KEYWORDS: English language proficiency, Mathematics teaching, LoLT.

\section{INTRODUCTION}

Durkin and Shire (1991: 3) state that mathematics education begins and proceeds in a language, and it advances and stumbles because of language, and its outcomes are often assessed in language. In as much as this notion applies to all learning areas, its crucial application in mathematics is highlighted in the example below:

While presenting a continuous professional teacher development course in mathematical thinking and problem solving, a lecturer assigned a group of Intermediate Phase (IP) mathematics teachers from the Eastern Cape Province of South Africa the following word problem to solve: 'Enzo a botte le ballon 4 fois. Nathan a botte le ballon 11 fois. Combien de fois ont-ils botte le ballon en tout?" On realizing that the teachers did not seem to understand the problem, some clues were provided to assist the teachers and the word problem read as follows: Enzo kicked le ballon 4 fois. Nathan kicked le ballon 11 fois. Combien de fois ont-ils kick le ballon en tout? 
After fruitless deliberations among the teachers, the lecturer provided a diagrammatic representation of the problem as illustrated in Figure 1:

Figure 1: A diagrammatic illustration of a word problem

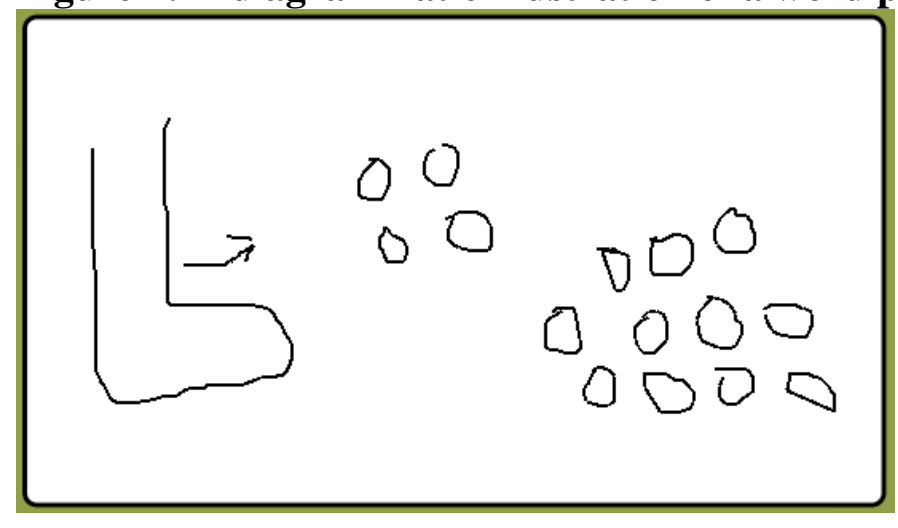

Adapted from Barwell, Leung, Morgan and Street (2002)

The added clues as presented in the diagram seemed to help the teachers and some responded to say the solution to the problem is 15 . When the lecturer requested an explanation for how they arrived at the answer 15, one teacher said it was through guesswork. The lecturer confirmed that the answer is indeed 15, and translated the French word problem into English: Enzo kicked the ball 4 times. Nathan kicked the ball 11 times. In total, how many times did they kick the ball? It was intriguing for the teachers to discover that the word problem that had seemed so problematic was actually a simple addition sum of $\mathbf{4}+\mathbf{1 1}=\mathbf{1 5}$, yet the teachers had to be provided with a few clues before they could guess the answer.

The example above attests to Durkin and Shire's (1991) notion: in the absence of a language barrier (French is a foreign language to the participants of the study) presented by the word problem, solving the addition sum would have been an easy task for the Intermediate Phase (IP) mathematics teachers and they would not have resorted to guesswork. Since mathematics education is pivoted on one's proficiency in the language in which the mathematics concepts and procedures are presented, how teacher language proficiency impacts on mathematics education in under-resourced provinces such as the Eastern Cape Province warrants interrogation.

Mathematics has a particular way of using language and its own particular way of expressing ideas, which is termed the mathematics register (Lee, 2006; Pimm, 1987). One way of describing the relationship between a natural language such as English and mathematics is in terms of the linguistic notion of register (Durkin \& Shire, 1991: 17). Therefore, mathematical language is considered a distinct 'register' within a natural language such as English, which is described as 'a set of meanings that is appropriate to a particular function of language, together with the words and structures which express these meanings' (Halliday, 1975: 65). Language proficiency is an individual's ability to speak, read, write, interpret and generally use a language well and efficiently. It is the quality of being adequately or well qualified to use a language for both basic communication tasks and academic purposes (DBE, 2010). Language proficiency also refers to the quality of great facility and competence (DBE, 2010). Thus proficiency requires higher levels of mastery than just the basics. Linguistic competence is an individual's implicit internalised knowledge of the rules of a language (DBE, 2010). In this article, the terms language Per Linguam 2019 35(3):106-124 
competence and linguistic competence are used interchangeably, and the focus is on the participating teachers' language proficiency in using English as a language to mediate meaningful mathematics instruction.

The article provides a brief description of teachers' language proficiency and mathematics instruction in South Africa, phase-level changes in the South African school education system, the research questions, conceptual framing, research design and methodology, findings and discussion.

\section{Perspectives on teachers' language proficiency iand mathematics instruction in South Africa}

According to Tshabalala, (2012: 22) the majority of teachers in South African schools are not first language speakers of English. This is not peculiar to South Africa only, but common practice in several sub-Saharan countries where English is used as a lingua franca and one of the languages of instruction in specifically from upper primary school up to tertiary level. Difficulty to communicate fluently in the LoLT leads to increased teacher frustration, a slow rate of learning, disciplinary problems and teacher-centred instruction (Setati, 2008; Howie, 2003). Thus, a mathematics teacher who is not competent in the language of instruction faces challenges in imparting mathematical concepts and procedures, and these challenges compromise the quality of instruction that takes place in the classroom. When teachers do not use mathematical language fluently, learners are unable to describe mathematical ideas using appropriate language (Murray, 2012; Howie, 2001).

\section{Phase Level Changes in South African School Education System}

South African schooling is divided into four levels: Foundation Phase (FP), from Reception to Grade 3, Intermediate Phase (IP) from Grade 4 to 6, Senior Phase (SP) from Grade 7 to 9 and the Further Education and Training (FET) band from Grade 10 to 12. Several changes take place during the change from FP to IP, such as an increase in the number of learning areas offered, and these learning areas are taught by different teachers [National Education Evaluation and Development Unit (NEEDU), 2013]. Of the several changes, this research highlights the change in the language of instruction as the most significant. Ninety percent of South African learners are not native English speakers, and their different home languages are used in the FP while from the IP onwards English is used as the official Language of Learning and Teaching (LoLT).

\section{Research Questions}

The aim of this research was to analyse IP mathematics teachers' language proficiency in the language of learning and teaching. The objective was to investigate the extent to which IP mathematics teachers in the Eastern Cape Department of Education (ECDoE) schools are proficient in English, the prescribed LoLT. The central research question was: To what extent are IP mathematics teachers in ECDoE schools proficient in English, the prescribed LoLT? For a deeper understanding of IP mathematics teachers' language proficiency, the following research sub-questions were formulated:

i. To what extent does proficiency in English, the prescribed LoLT relate to English symbol obtained at matriculation?

Per Linguam 2019 35(3):106-124

http://dx.doi.org/10.5785/35-3-849 
ii. To what extent does proficiency in English, the prescribed LoLT relate to initial teacher education qualification?

iii. To what extent does proficiency in English, the prescribed LoLT relate to experience in teaching IP mathematics?

\section{Conceptual Framing}

This section provides the conceptual framing that informs the need to focus on the language competence/proficiency of IP mathematics teachers. Many studies only outline the characteristics, process and application of learner-language competence, however, very few studies focus on the language competence of mathematics teachers, who are direct and indirect products of the South African education system. The conceptual frameworks for investigating language issues in mathematics that can be employed in diverse language contexts, specifically here the South African context, can help to interpret the findings emerging from a particular context, such as the Eastern Cape Province, hence the significance of this research. The conceptual frameworks presented can be employed to investigate other bilingual and multilingual learning contexts. Given the increasing number of ELLs receiving education in a dominant language that is not their own first language, (Adler, 2001), these findings are important for mathematics education particularly for exploring the needs of IP mathematics teachers' language usage and development which in turn determine their quality of instruction. The conceptual frameworks grounding the research are Cummins's (2000) Linguistic Threshold Hypothesis and Gawned's (1990) Socio-Psycho-Linguistic Model.

\section{Linguistic Threshold Hypothesis: Cummins (2000)}

The broad theoretical framework referred to in this research is Cummins's threshold hypothesis (Cummins, 2000) which indicates that a threshold level of second language is necessary for the home-language reading skills and knowledge to transfer to second-language reading. A lack of second-language knowledge 'short circuits' the use of the home-language linguistic skills (Pretorius \& Mampuru, 2007: 42; Bernhardt \& Kamil, 1995: 17). This hypothesis assumes that language proficiency is the key factor in reading activities and, therefore, for one to be able to read a language, one needs to know the language at a certain level of proficiency.

The relevance of the linguistic threshold hypothesis on the research design and methodology employed by this study considers that the majority of the IP mathematics teachers referred to in the study are supposedly bilingual, and more specifically multilingual. The language they are prescribed to teach in, namely English, is not their home language, and it is also not the home language of the majority of the learners they teach. The home language shared by the majority of the teachers and learners in the Eastern Cape Province is isiXhosa, and by default isiXhosa is the LoLT used at FP level. Cummins's (2000) hypothesis recognises the importance of investigating both languages of learning and their influence on the quality of mathematics learning. Given that the IP mathematics teachers in this study must manage the transition from mathematics instruction through the medium of isiXhosa at FP level to instruction through the medium of English at IP level, this hypothesis best reflects the situation present in the Eastern Cape Province of South Africa.

\section{Socio-Psycholinguistic Model: Gawned (1990)}

Per Linguam 2019 35(3):106-124

http://dx.doi.org/10.5785/35-3-849 
Gawned's (1990) socio-psycho-linguistic framework is based on a model of language learning. The current research employs the socio-psycho-linguistic framework as it best reflects the nature of interaction between natural language and the mathematics register (mathematical language), and the way that language can influence mathematics learning and understanding as illustrated in Figure 2.

Figure 2: A summary of the socio-psycho-linguistic model (Gawned, 1990)

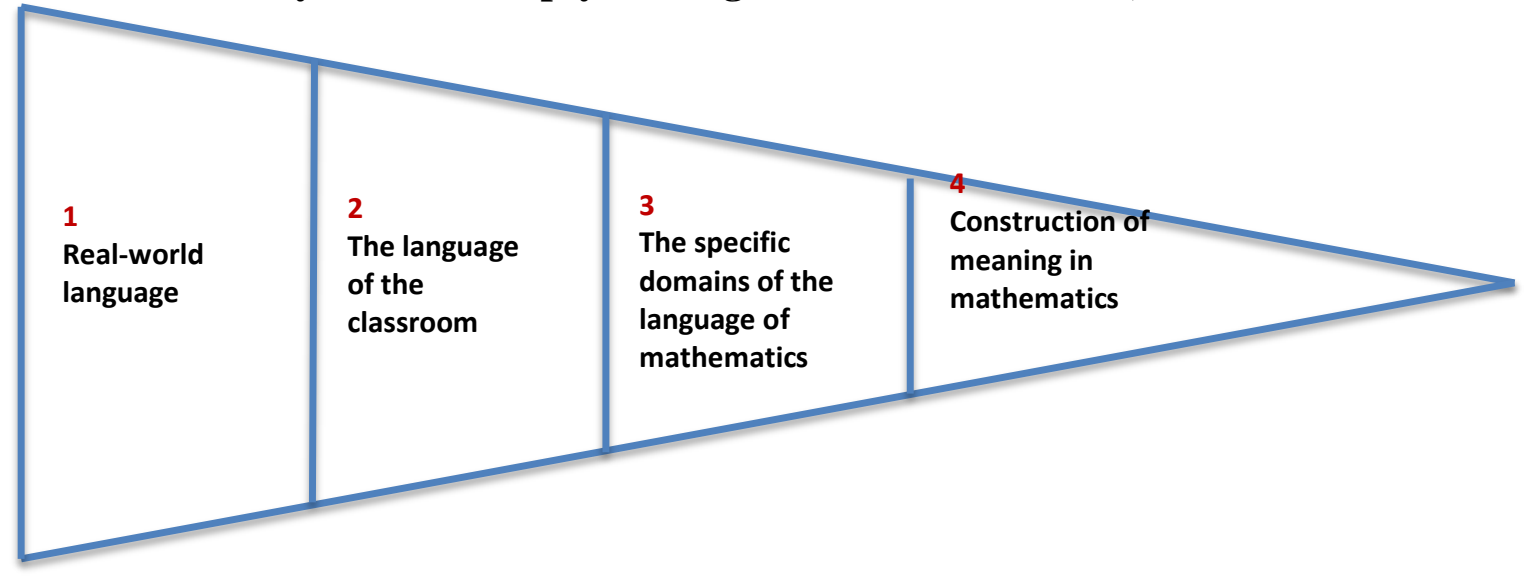

Particularly important in Gawned's (1990) model is its acknowledgement that the language of the classroom has a great influence on learners' understanding of mathematics, and that each classroom has a unique culture. Gawned's (1990) model also discusses the discourse patterns found in mathematics classrooms. Gawned's (1990) model reflects the nature of mathematics classrooms and the way that language plays a key role in learning, particularly the language of the teacher and the textbook, while also highlighting the cultural influences on mathematics education.

Viewing IP mathematics instruction as a socio-psycho-linguistic process emphasises the construction of meaning and draws upon an individual's unique constellation of prior knowledge, experience, background and social contexts. Thus, the socio-psycho-linguistic process is holistic instead of being focused on discrete parts. If teachers understand mathematics instruction as a socio-psycho-linguistic process, then they will be in a better position to incorporate the linguistic elements of mathematics instruction into their classroom practice. As classroom teachers teach mathematics as a socio-psycho-linguistic process, a component of their learners who will end up in teaching and academic careers, will also be inclined to adopt that method. As this approach becomes cumulative and widespread, it could revolutionise the way mathematics is taught and learned.

Both Cummins's (2000) and Gawned's (1990) frameworks demonstrate how language and the language of instruction are key areas in the learning and teaching of mathematics. This has implications for the mathematics learning and teaching process through the medium of a second language, particularly using English as a LoLT. Without discrediting the contribution made by the two frameworks in understanding language issues in mathematics education, one cannot be 
blind to the fact that South Africa, and the third world in general, have contextual socioeconomic factors that impact on education which might have been overlooked in western contexts.

\section{RESEARCH DESIGN AND METHODOLOGY}

By focusing on a particular province, the research also has elements of a case study embedded in it. The Mount Frere district in the Eastern Cape Province was chosen for this study because it had been the worst performing in the country in 2013, with 47,5\% of the Grade 6 learners classified as 'not achieved' in mathematics Annual National Assessments (ANA) ${ }^{\mathrm{ii}}$, (DBE, 2015). Based on the Eastern Cape Province's recurrent poor performance in mathematics, this investigation of mathematics teachers' language proficiency in the prescribed LoLT was designed as a case study in order to zoom into, and better understand the situation in the province. Ethical clearance to collect data was obtained from University of Stellenbosch Research Ethics Committee and ECDoE Strategic Planning Policy Research and Secretariat Services. The data collection techniques included an English language proficiency assessment (for participating teachers) and a questionnaire focusing on demographic data.

The English language proficiency assessment was provided by JET Education Services. It is a standardised teacher assessment, conforming to the South African context and piloted in five different university teacher-education departments in the country. The assessment is primarily based on the National Curriculum Statement (NCS) home language level assessment standards for Grade 7 level. The rationale used is that teachers, at the absolute minimum, need to show a proficiency in a language that is two years beyond that of their learners (JET, 2015). The assessment comprised 47 items and covered a range of topic areas including comprehension, text structures, vocabulary, grammar and writing. Test items consisted of openended and multiple-choice questions. The level of the assessment is quite low, as it is aimed at establishing the absolute minimum standards for teachers. In view of the fact that the study participants are qualified and practicing teachers, the pass rate was set at $70 \%$.

The teacher demographic questionnaire was developed by the researcher to collect data on gender, age, race group, education districts, home language(s) spoken, university attended, highest qualification obtained, English symbol obtained at matriculation and experience in teaching IP mathematics.

The data collected were analysed using STATISTICA (2016) at University of Stellenbosch's Centre for Statistical Consultation, while JET Education Services conducted descriptive analyses of the quantitative data. Trends emerging from the two independent analyses of the quantitative data were compared and analysed qualitatively. 


\section{Sampling}

Research participants were selected using non-probability purposive sampling and the unit of analysis was language proficiency of 55 IP (Grade 4 -6) mathematics teachers from the ECDoE. These teachers were deemed appropriate for the research because they are based in poorly performing ECDoE schools, known to experience recurrent low performances in General Education and Training (GET) mathematics. The teachers were selected by ECDoE officials to attend continuous professional teacher development courses at the African Institute for Mathematical Sciences Schools Enrichment Centre (AIMSSEC) for the purposes of improving their mathematics content knowledge as well as teaching strategies most relevant to poorly resourced schools. For the purposes of this research, the teachers were studied not so much for their mathematics content knowledge, but rather to determine whether they were competent and proficient in using English as the LoLT in mathematics instruction. The section below details the IP mathematics teacher participants' demographic information.

\section{Demographic data of research participants}

Of the 55 teacher participants, $89 \%$ were female and $11 \%$ were male. $3 \%$ were below the age of 25, $2 \%$ were between 26 and 29, $2 \%$ were between 30 and 34, and the majority (93\%) of the participants were above 35 . The majority (96\%) of the participants belonged to the black race group, $2 \%$ were Coloured, $2 \%$ were white and none were Indian. The distribution of participants across race groups is closely related to the participant teachers' home languages. IsiXhosa is home language to $91 \%$ of the participants, seSotho to $7 \%$ of the participants and Afrikaans to $2 \%$ of the participants. It can be inferred that teachers of the black race group constituted those whose home language is isiXhosa and seSotho, while the participants of the coloured and white race groups constituted those speaking Afrikaans as their home language.

The Eastern Cape is a relatively large province divided into 24 districts. The districts where the participant teachers were deployed are indicated in Figure 3. 
Figure 3: Histogram of teacher participants' school districts

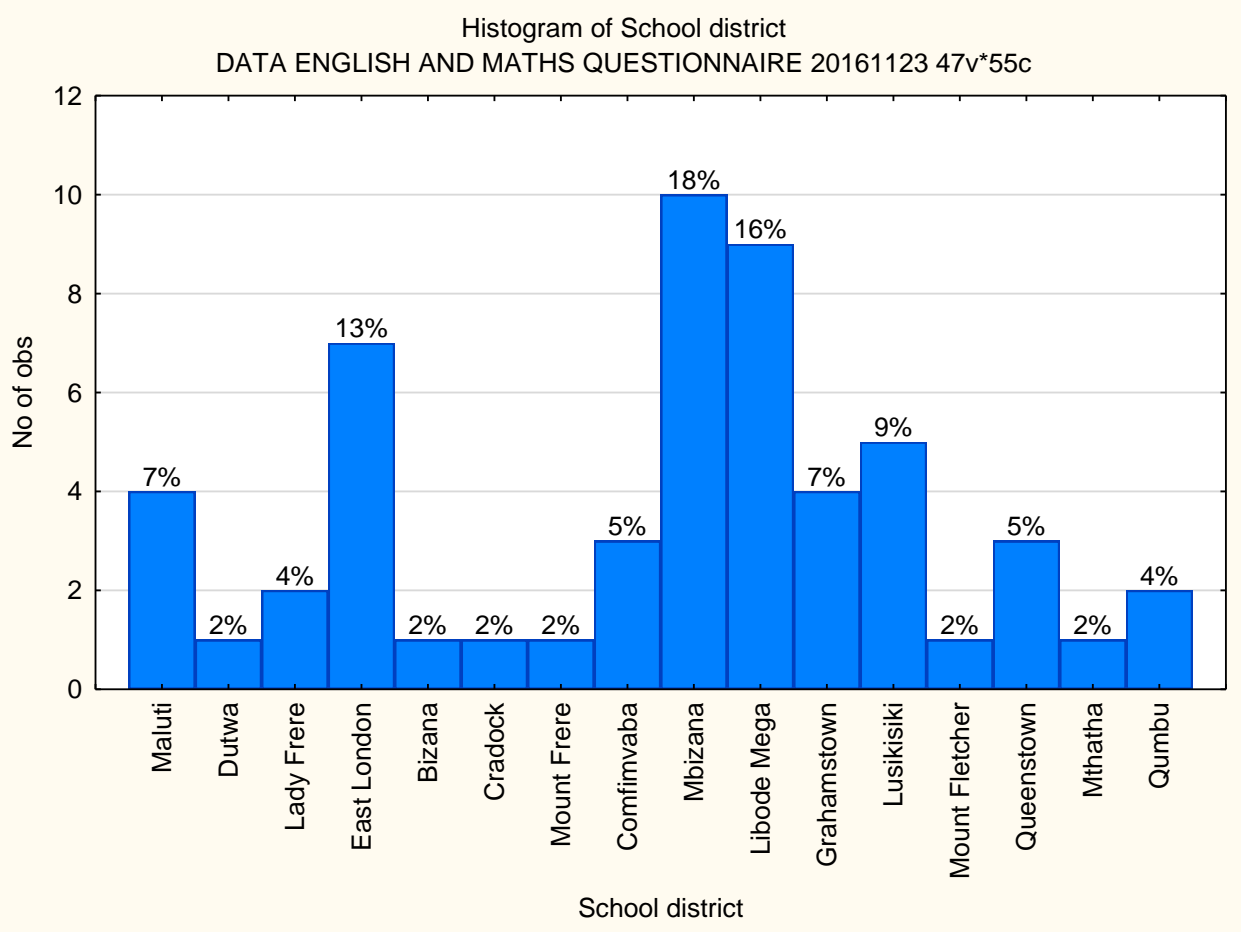

The teachers were from only 16 of the 24 education districts in the Eastern Cape Province (the full list of districts: Bisho, Butterworth, Cofimvaba, Cradock, Dutywa, East London, Fort Beaufort, Graaff-Reinet, Grahamstown, King William's Town, Lady Frere, Libode, Lusikisiki, Maluti, Mbizana, Mt Fletcher, Mt Frere, Mthatha, Ngcobo, Port Elizabeth, Queenstown, Qumbu, Sterkspruit and Uitenhage).

Twenty seven percent of the teachers studied at Teachers Colleges, which have since been closed after policy changes stipulating that all Initial Teacher Education (ITE) programmes be offered by the various university departments of education. Twenty five of the teachers studied at University of South Africa, 10\% of the teachers studied at University of Pretoria, while 5\% of the teachers studied at University of Zululand. For finer details regarding the teachers' level of education, information on their highest qualification obtained in teacher education was captured. The majority of teachers (49\%) only had a Diploma in Education, 15\% had a Bachelor's Degree in Education and 36\% had either an Advanced Diploma or an Honours' degree. According to these statistics, all the teachers were qualified including two outliers: an Adult Basic Education and Training (ABET) $)^{\mathrm{iii}}$ trained teacher and a teacher currently enrolled for a Masters degree in Education.

Since the current research is based on interrogating the teachers' proficiency in English, the prescribed LoLT in most South African schools, it was necessary to capture the symbols the

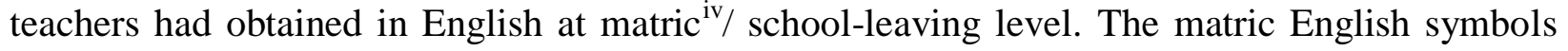
are indicated in Figure 4. 
Figure 4: Histogram of English symbols obtained at matriculation

Histogram of 16 ENGLISH SYMBOL

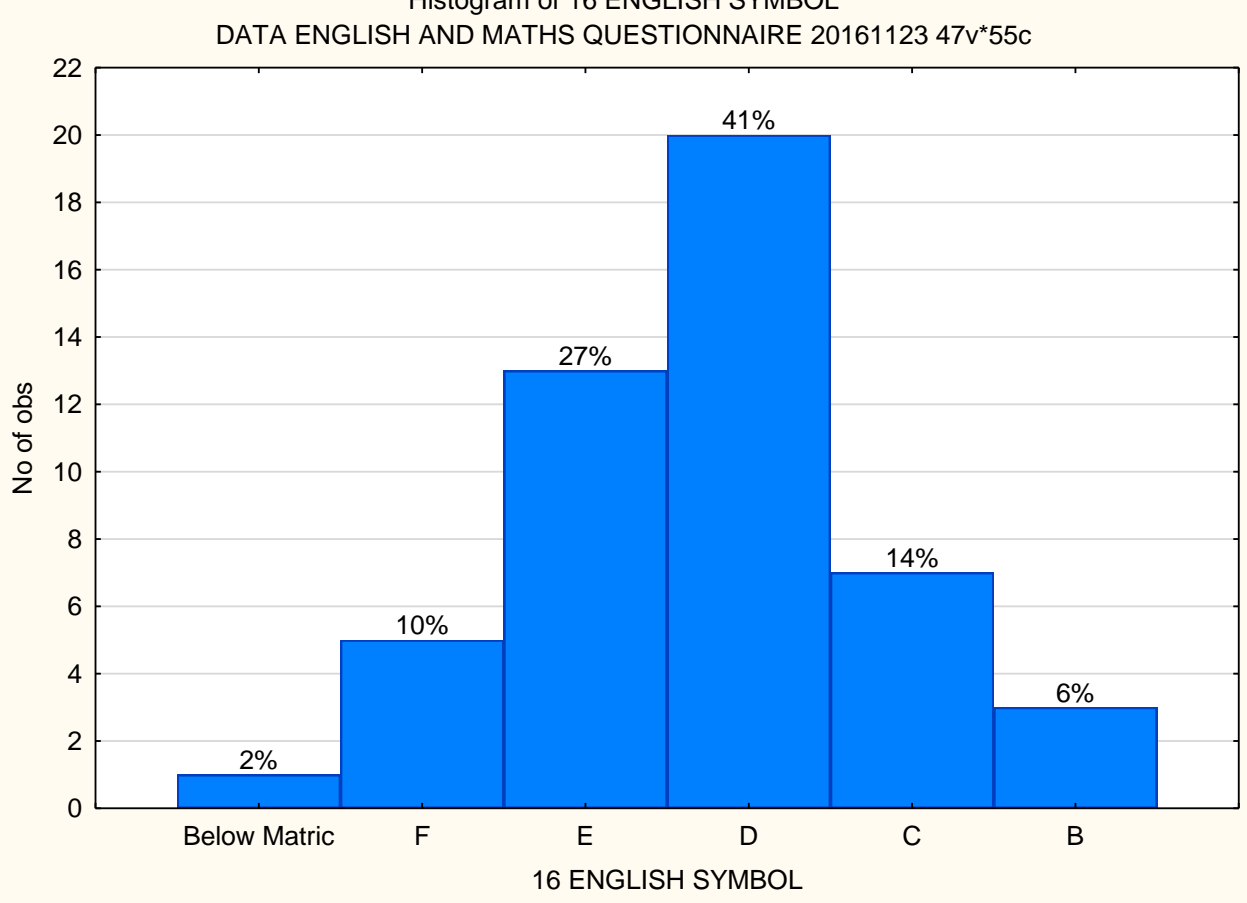

None of the teachers obtained symbol A, $6 \%$ obtained symbol B, $14 \%$ obtained symbol C, $41 \%$ obtained symbol D, $27 \%$ obtained symbol E, $10 \%$ obtained symbol F, and $2 \%$ failed matric English. It is noteworthy that the majority of the teachers obtained symbol $\mathbf{D}$ and below. However, as established in previous research, matriculants who settle for teacher education qualifications are usually not the crème de la crème (Tshuma, 2017), and more than half of South African teachers indicated that teaching was not their first profession of choice (Ainley and Casterns, 2018). Figure 4 provides information to confirm these attestations.

To ascertain the participants' teaching experience, the number of years they have been practising as IP mathematics teachers was captured. Nineteen percent of the participants had been teaching IP mathematics for two years and less, this could be attributed to the fact that some teachers could have been teaching other phases and/or subjects such as Technology and were moved to teaching IP mathematics when their subject specialisations were removed from the curriculum. Thirty two percent of the participants had been teaching IP mathematics for an average of five years, while $27 \%$ of the participants had been teaching IP mathematics for an average of 12 years, and these could be considered as seasoned IP mathematics teachers. The section below outlines the study limitations and delimitations.

\section{Limitations}

The research's limitation was that some male teachers were not as enthusiastic during the language competency assessment, and thus affected gender balance. The delimitation was focusing on one province in South Africa while there are other poorly performing provinces such as Limpopo and KwaZulu-Natal, (DBE, 2015). For more conclusive results, the research could 
have compared teacher performance in both under-resourced and well-resourced provinces as there could be other extraneous factors that could have contributed to teacher competency in the language of instruction. For example, it could be argued that well-resourced provinces that have embraced teaching and learning technology could be in a better position to produce better results compared to their counterparts.

\section{FINDINGS}

The research question was: To what extent are IP mathematics teachers in ECDoE schools proficient in English, the prescribed LoLT? The key finding was that sampled teachers indeed exhibited a lower proficiency than what is expected of a Grade 7 learner. Based on JET's performance scales, a consolidation of these performance scales is presented in Table 1:

\section{Table 1: English Proficiency assessments scores}

\begin{tabular}{|l|c|}
\cline { 2 - 2 } \multicolumn{1}{c|}{} & English Language Proficiency Scores \\
\hline $\mathbf{7 0} \%$ and above & $(0) 0 \%$ \\
\hline $\mathbf{5 0} \%-\mathbf{6 9} \%$ & $(6) 11 \%$ \\
\hline Below 50\% & $(49) \mathbf{8 9} \%$ \\
\hline
\end{tabular}

Key

$-70 \%$ and above: satisfied requirements

- 50\% - 69\%: cause for some concern

- Below $50 \%$ : cause for serious concern

None of the teachers met the satisfactory requirements in the English language proficiency assessment. While $11 \%$ of the teachers scored between $50 \%-69 \%$, and thus provide some cause for concern, $89 \%$ of the teachers scored below $50 \%$. In other words, the majority of the teachers' English language proficiency is a major cause for concern. These consolidated scores reiterate that much more still needs to be done to improve the language proficiency of IP mathematics teachers.

The teachers' English language proficiency scores are presented in a histogram in Figure 5 in order to present the nature of the distribution of the scores as well as to identify possible outliers: 
Figure 5: Histogram of English language assessment \%

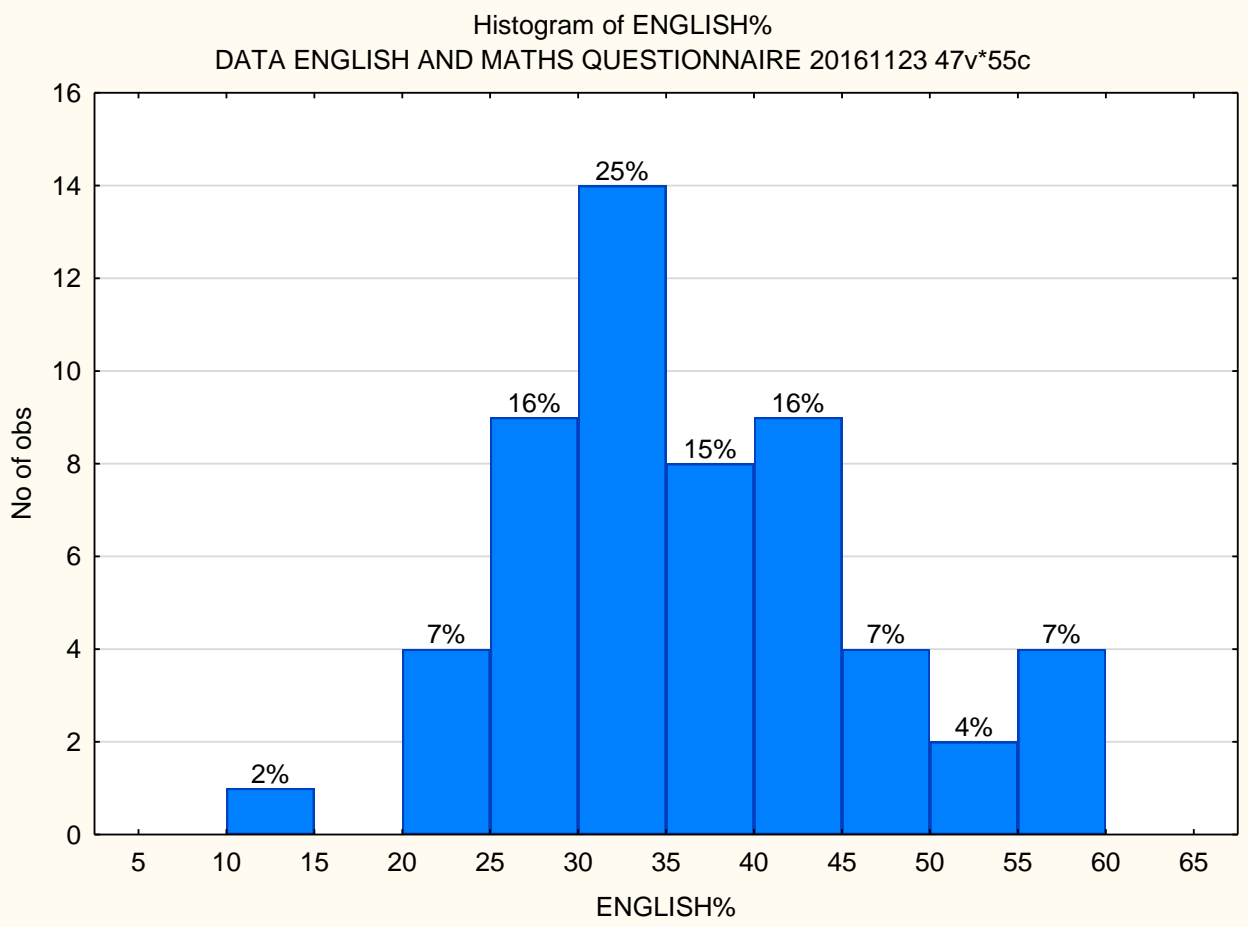

Out of the 55 teachers who wrote the test, the minimum score obtained was $\frac{9}{80}=11 \%$, while the maximum score was $\frac{48}{80}=60 \%$. It is troublesome to note that on average, teachers exhibited a lower proficiency than what is expected of a Grade 7 learner.

Research analysing initial teacher education across five South African universities reveals that '... the situation with respect to the language of learning and teaching, predominantly English, is of particular concern' (Taylor, 2015: 23). The participants' English language proficiency as exhibited in Figure 5 confirms Taylor's findings. However, merely establishing and / or confirming this low proficiency level is but the beginning. More needs to be done to change the status quo and ultimately contribute to the improvement of teacher classroom practice.

\section{Teacher Proficiency in the LoLT and English Symbol in Matriculation}

Demographic data presented the teacher participants' English language symbols obtained at matriculation. The data on teacher English language matriculation symbols were correlated to the teacher English language proficiency scores. Figure 6 illustrates the correlation between the teachers' English language proficiency level versus English symbols obtained at matriculation. 
Figure 6: English symbol at matriculation vs English Language proficiency assessment means

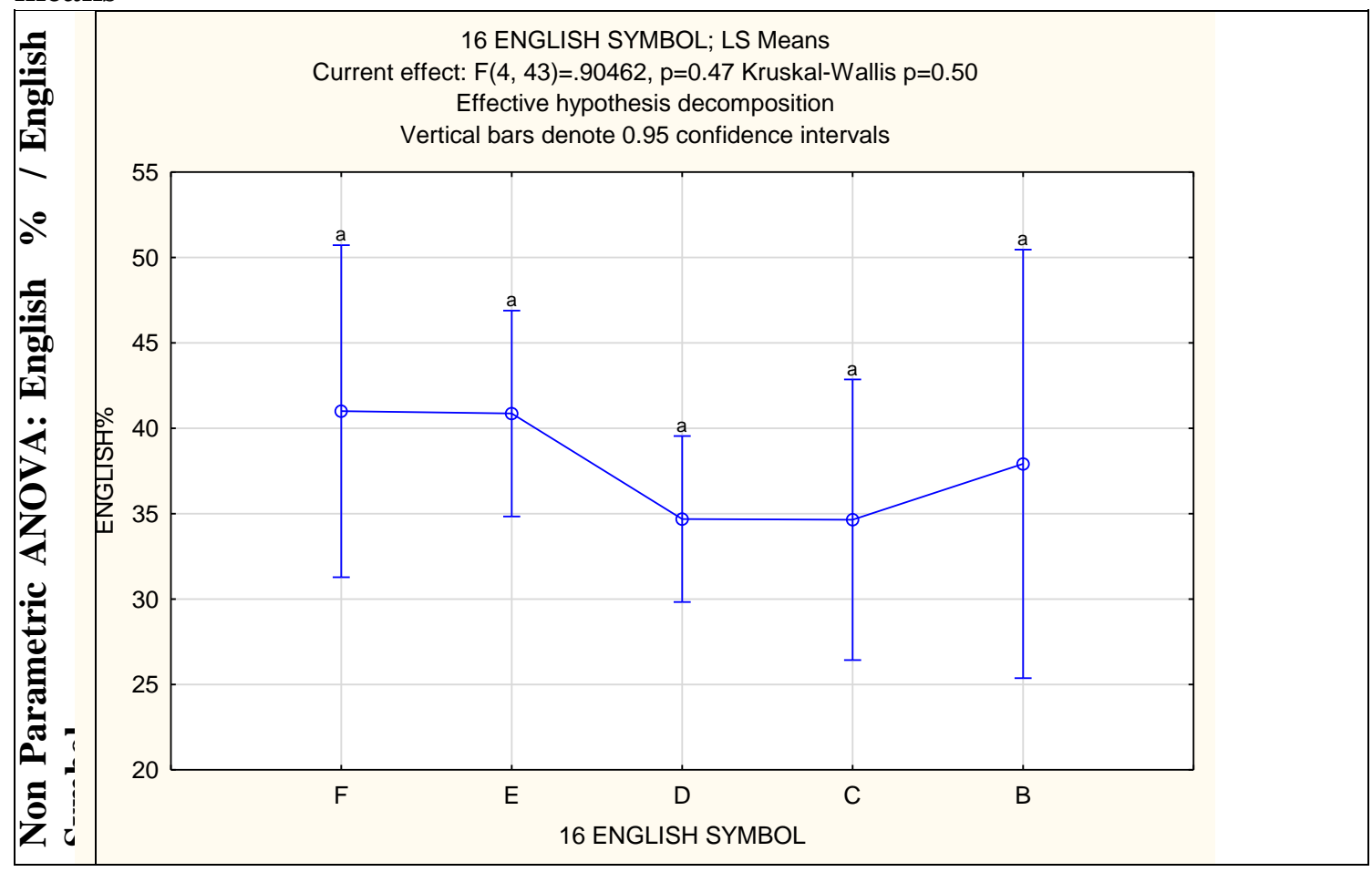

In the demographic data it was established that the majority of the teachers obtained a $\mathbf{D}$ symbol and below, and the group that obtained the D symbol has the lowest LS mean, thus there is a correlation between the matric English symbol and the English language proficiency level.

\section{Teacher Proficiency in the LoLT and Teacher Initial Education Qualification}

Closely related to the matric English symbol obtained is the teacher qualification as established in participant demographic data. According to the demographic information, all the participant teachers are qualified, however, the learner performance at GET level as detailed in literature is significantly low, thus a gap exists. The fact that all participants are qualified teachers is a good starting point, however, if these qualified teachers are exhibiting language deficiencies as indicated in the teachers' language proficiency assessment, it means there is still more that needs to be done. Thus, the qualifications provide a good starting point to further develop the teachers to become better classroom practitioners in order to bridge the gap between the qualified teachers and the significantly low learner performance at GET level. The next steps should be a review of the teacher education curriculum during and after ITE in order to provide modules that will linguistically upskill teachers for the purposes of changing the status quo.

With regard to the two outliers identified in the demographic section, the ABET trained teachers who ended up in mainstream classroom teaching are recommended for furthering their studies and alleviating the shortage of mathematics teachers. This research envisages that such teachers need special upskilling in order to cope with the demands of mainstream classrooms. The 
requirements of an ABET course are not the same as those of a formal curriculum and therefore, their upgrading into the mainstream curriculum teaching posts needs to be sufficiently supported. On the other hand, one of the participants was in the process of completing a Masters Degree in Education. By virtue of being in the process of completing such a high-level qualification, it would have been expected of this participant to obtain relatively higher marks in a basic English language proficiency assessment, however, this was not the case, and arguably a possible cause for concern.

\section{Teacher Proficiency in the LoLT and IP Mathematics Teaching Experience}

Demographic data statistically analysed the teacher participants' experience in teaching IP mathematics. The data on experience in teaching IP mathematics were correlated to the teacher English language proficiency assessment scores. Figure 7 illustrates the correlation between English language proficiency levels versus experience in teaching IP mathematics.

Figure 7: Correlation between experience (Years) vs English \%

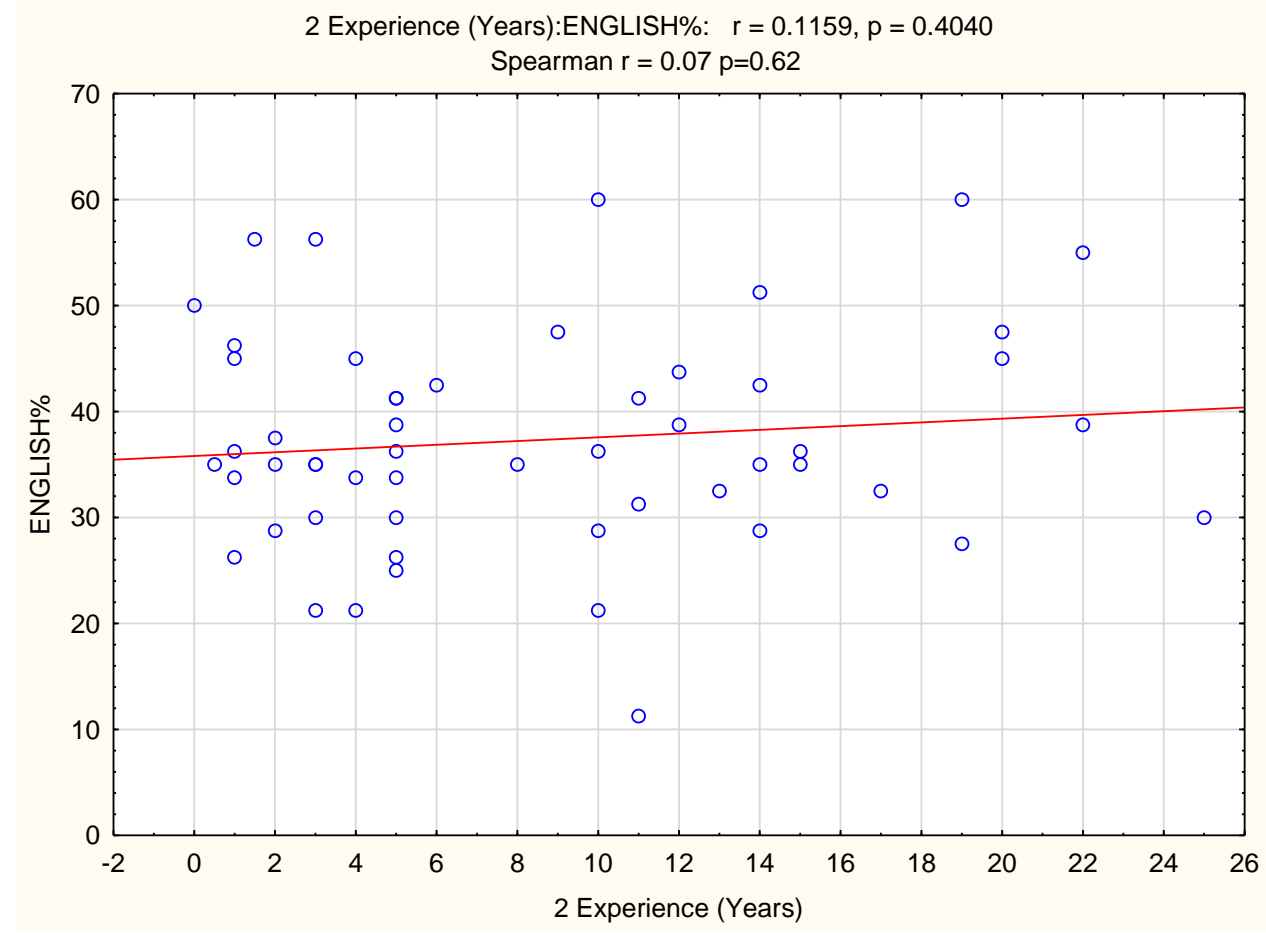

As established in the demographic data section, about $60 \%$ of the participants are experienced teachers who have been teaching IP mathematics for between 5 and 12 years. As illustrated in Figure 7 , with a correlation coefficient of $r=0.1159$, there is a positive correlation between English language proficiency and experience in teaching IP mathematics. This correlation implies that as teachers gain more experience in teaching mathematics, their proficiency in the English language somewhat improves - this could be attributed to the exposure the teachers gain as they engage with the teaching and learning content. Further research is needed to establish and 
confirm to what extent prolonged exposure to teaching and learning content alone improves teachers' language proficiency in the LoLT.

The sections above provided information gathered through the teacher English Language Proficiency assessments by initially analysing the raw scores and then relating the scores to data collected from the teacher demographic data questionnaires. The section below presents samples of teacher responses from sub-Section E of the English Language Proficiency Assessment with a total achievable mark of [4]. Although forming part of the English language proficiency assessment, the question was based on a typical lower cognitive demand mathematical word problem which requires simple recall of facts and interpretation of tabulated information as illustrated in Table 2:

Table 2: Sample Teacher Responses to a typical English Language Proficiency Assessment Question

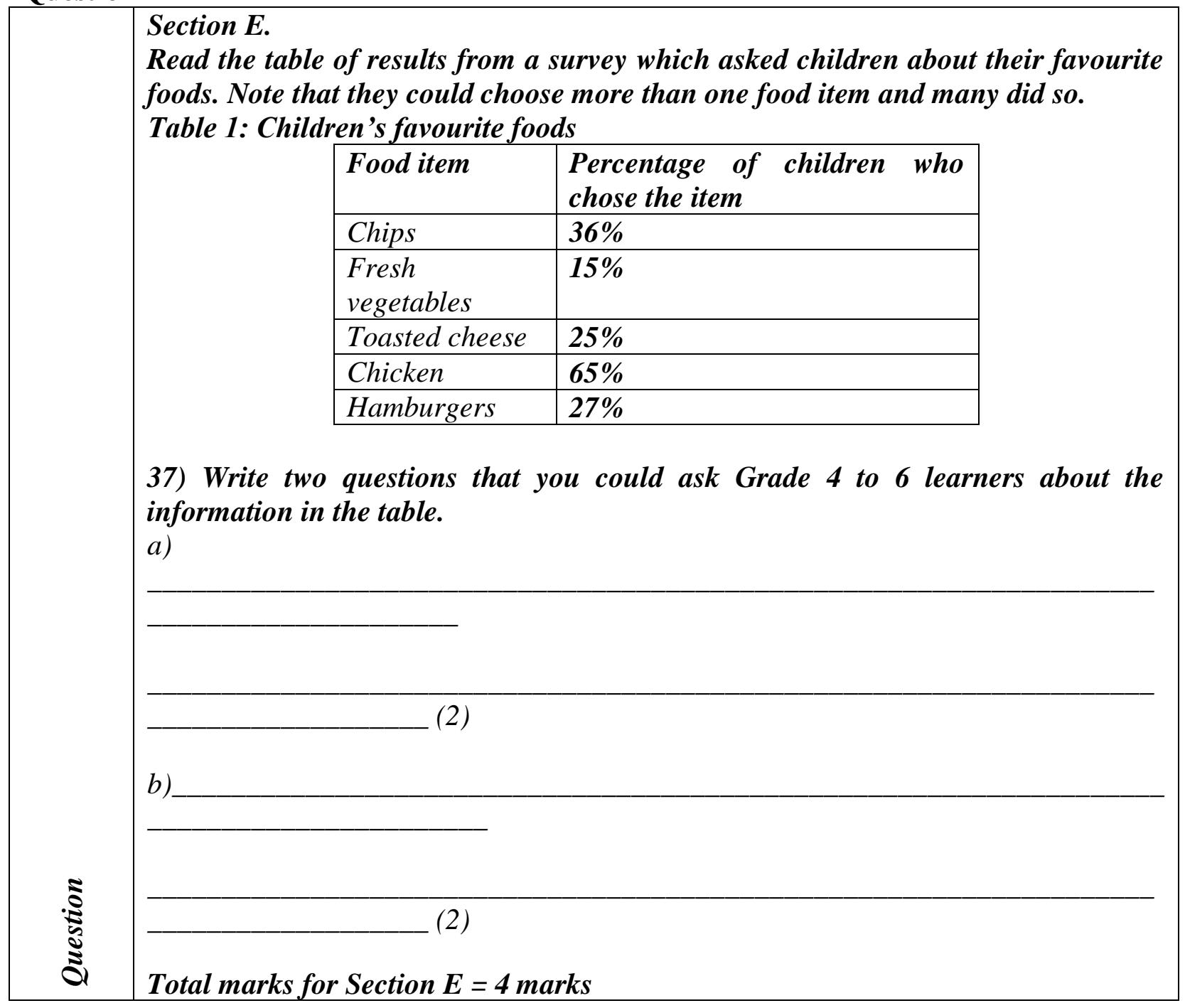




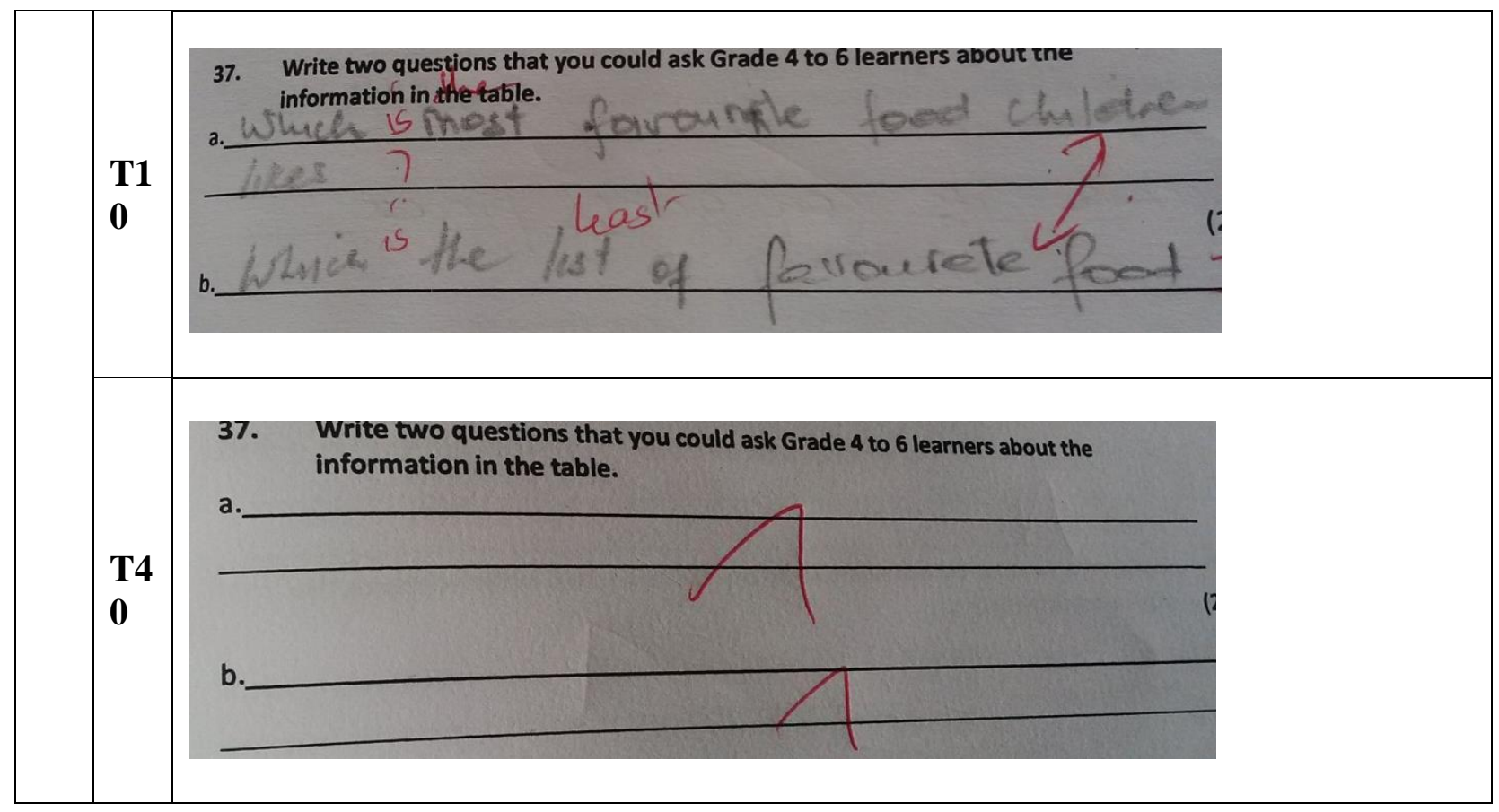

Adapted from (JET, 2015)

The sample responses illustrated in Table 2 exhibit a variety of linguistic challenges ranging from spelling mistakes, punctuation (omission of the question mark), grammatical mistakes, repetition and duplication of information, provision of information that does not answer the question, incomplete answers and unattempt to answer questions. Thus the participating teachers' language proficiency/competence could be described as bordering on mediocrity as portrayed in the language competency assessment. However, the assessment component illustrated above (sub-section E) had the highest scores. This seems to indicate that teachers are relatively comfortable answering questions with lower-order linguistic demands - a question type that represents only a minority of the teaching and learning content at IP level. In as much as the relatively high performance in lower-order questions is commendable, IP teachers need to broaden their command of the English language to include more higher-order questions for the purposes of improving the quality of instruction.

\section{RECOMMENDATIONS}

The aforegoing sections presented the findings from the current research. The section that follows presents the recommendations based on these findings. These recommendations focus on the different target audiences in initial teacher education, namely: prospective IP mathematics teachers, pre-service IP mathematics teachers, in-service IP mathematics teachers as well as decision makers responsible for deploying newly qualified teachers.

\section{Prospective IP Mathematics Teachers at Registration Level}

English second language speakers' academic success is dependent on their proficiency and competency in academic language (Brown, 2007). Against the backdrop of the South African education system, providing essential skills that will ensure language competency among 
aspirant IP mathematics teachers would be a positive way of modelling good practice for emulation by the teachers in their own classroom settings where the majority of the learners are second language speakers of the English language. Low levels of academic performance and unsatisfactory overall rates in some South African schools and institutions of higher learning suggest that responses to the teaching and learning needs of underprepared learners are not sufficient (Eid, 2012; Parades, 2010; SAUVCA, 2003). At university registration, prospective IP mathematics teachers should have good marks in matric/Grade 12 English. If due to quota systems enrolment includes prospective teachers with below average marks in the language of instruction, language bridging courses should be introduced to ensure that prospective teachers attain the required minimum level.

\section{Pre-service IP Mathematics Teachers}

With a maximum of $60 \%$ and a minimum of $11 \%$ obtained in the teacher English language competency assessment in this study, teachers revealed a lower proficiency in English than what is expected of a Grade 7 learner. Even though English is a foreign language to the majority of the teachers who use it as language of instruction in South Africa, the mere fact that the current LiEP requires teachers to use English as the medium of instruction calls for high levels of proficiency in that language. The Minimum Requirements for Teacher Education Qualifications (MRTEQ) ${ }^{\mathrm{V}}$ policy documents require IP teachers to at least have Additional Language proficiency in English, and prescribes that one of the competencies of a newly qualified teacher is to 'know how to communicate effectively in general, as well as in relation to their subject(s) in order to mediate learning' (MRTEQ, 2015: 20). However, the answers provided by the teachers in the English Language Proficiency Assessment revealed grammatical and idiomatic errors, which seem to indicate that the Additional Language proficiency of teachers in this study is not sufficient for an IP mathematics teacher using English as the LoLT. Therefore, student teachers currently enrolled for IP mathematics education courses need to be upskilled in the prescribed LoLT. While this study focused on English as the LoLT at IP level, proficiency in any LoLT is a requirement for effective instruction.

\section{In-service IP Mathematics Teachers}

Since South Africa's democratisation in 1994, English has become the lingua franca in public life and the language prevails as the LoLT at primary and secondary school levels as well as in higher education (Cuvelier, Du Plessis and Teck, 2003). With many educational institutions in a state of change, Cuvelier et al, (2003) further contend that School Governing Bodies (SGB)s are mandated the power to decide on the LoLT for their schools. A common practice that has been adopted by most SGBs is additive bilingualism, where the FP is taught in the mother tongue, while English is taught as a first additional language in preparation for a transition that takes place in the IP where English becomes the LoLT. While this is a plausible attempt to balance the attention given to marginalised languages, SBGs and School Management Teams (SMTs) that have adopted this policy need to further support it by mandating stakeholders in teacher education to ensure the transition is smooth enough and does not compromise the quality of IP mathematics teaching and learning. 


\section{Decision Makers Responsible for Newly Qualified IP Mathematics Teachers' Deployment and Class Allocation}

Proficiency in English is necessary for teachers to engage in high quality mathematics instruction in English. The fact that the majority of South African teachers (and learners) in ordinary schools are not first-language speakers of English, but are prescribed to use English from the IP level onwards without much preparation for the phase change presents a gap in policy, practice and research. Addressing this gap needs to be prioritised for meaningful mathematics education to take place in multilingual IP classrooms. At school level, SMTs must use proficiency in English as one of the selection criteria used to allocate Grade 4 (the entry level of IP) mathematics teachers. Education officials responsible for deploying newly qualified IP mathematics teachers in under-resourced schools should ensure that these teachers have a firm grasp of the language of instruction. If not, these teachers should be enrolled for continuous teacher development courses that prioritise proficiency in the language of instruction.

This study supplements the current body of knowledge regarding language in mathematics education in general, and specifically on teacher-language competencies in the prescribed LoLT. Without promoting hegemony or dominancy of the English language, urgent measures need to be put in place to capacitate pre-service as well as in-service IP mathematics teachers to be confident and proficient in the use of English as LoLT, especially at IP level where the transition from mother-tongue to second-language instruction occurs. Failure to prioritise these important issues will continue to see South Africa occupying the lowest position in mathematics and science education (TIMSS, 2013) compared to other sub-Saharan countries. Without drastic changes, under-resourced schools, staffed by under-qualified teachers will continue to produce learners with sub - standard education who cannot cope with the demands of tertiary education.

\section{CONCLUSION}

Teachers' language proficiency in the prescribed language of instruction is a critical, but often overlooked aspect of teaching and learning IP mathematics. To avoid settling for mediocrity, trivialising mediocre education standards as if they are the norm or guessing what the LoLT requires of them, teachers need to be proficient enough in the language of instruction. However, teachers cannot do this without the support of other stakeholders in education. This article challenges didacticians, teacher educators, educational linguists and teacher education curriculum developers to provide adequate linguistic preparation and support to pre-service as well as in-service mathematics teachers for the attainment of language skills which can be used to improve mathematics instruction. Teachers who are confident and proficient in the LoLT are better able to deal with the linguistic needs of IP learners within the South African education system and are more likely to produce better results.

\section{REFERENCES}

Adler, J. 2001. Teaching Mathematics in Multilingual classrooms. Dordrecht: Kluwer Academic Publisher.

Ainley, J. \& Casterns, R. 2018. The OECD Teaching and Learning International Survey, (Talis). Available from www.oecd.org; [Accessed: 12 July 2019]. 
Barwell, R, C Leung, C Morgan \& B Street. 2002. The Language dimension of mathematics teaching. Mathematics Teaching 180: 12-15.

Bernhardt, EB \& ML Kamil. 1995. Interpreting relationships between L1 and L2 reading: Consolidating the linguistic threshold and the linguistic interdependence hypotheses. Applied Linguistics, 16: 15 34.

Brown, HD. 2007. Principles of language learning and teaching. White Plains, NY: Pearson Longman.

Cummins, J. 2000. Language, power and pedagogy: Bilingual children in the crossfire. Clevedon: Multilingual Matters.

Cuvelier, P, T du Plessis \& L Teck. 2003. Multilingualism, Education and Social Integration. Belgium, Europe, South Africa. Pretoria: Van Schaik.

Department of Basic Education (DBE). 2010. The status of the Language and Learning and Teaching (LoLT) in South African public schools: A quantitative overview. Pretoria: Department of Basic Education.

Department of Basic Education (DBE). 2015. Education Statistics in South Africa. Pretoria: Education Management Information Systems.

Dell Inc. 2016. STATISTICA (data analysis software system), version 13. http://www.statsoft.com/

Eid, A. 2012. Language learning strategy use of Saudi EFL students in an intensive English learning context. Asian Social Science, 8 (13): 115 - 127.

Gawned, S. 1990. An emerging model of the language of mathematics. J. Bickmorebrand (Eds.), Language in mathematics (27-42). Carlton, VIC: Australian Reading Association.

Government Gazette Number 38487. 2015. National Qualifications Framework Act (67/2008): Revised policy on the Minimum Requirements for Teacher Education Qualifications (MRTEQ), Pretoria: Republic of South Africa.

Halliday, M. A. K. 1975. Some aspects of sociolinguistics. In E. Jacobsen (Ed.). Interactions between linguistics and mathematical education: Final report of the symposium sponsored by UNESCO, CEDO and ICMI, Nairobi, Kenya, September 1-11, 1974 (UNESCO Report No. ED-74/CONF.808, 64-73). Paris: UNESCO.

Howie, S. J. 2001. Mathematics and Sciences Performances in Grade 8 in South Africa: TIMSS-R 1999 South Africa. Pretoria: Human Sciences Research Council.

Howie, S. J. 2003. Language and other background factors affecting secondary pupils' performance in Mathematics in South Africa, African Journal of Research in Mathematics, Science and Technology Education, 7 (1): $1-20$.

JET Education Services, (2015). Intermediate / Senior Phase Teacher Assessment, English. Initial Teacher Education Research Project. Johannesburg: JET Education Services.

Lee, C. 2006. Language for Learning Mathematics: Assessment for Learning in Practice. New York: Open University Press.

Murray, H. 2012. Problems with Word Problems in Mathematics. Learning and Teaching Mathematics, 13: $55-58$.

National Education Evaluation and Development Unit (NEEDU). 2013. National Report 2013: Teaching and Learning in Rural Primary Schools. Pretoria: National Education Evaluation and Development Unit.

Parades, E. 2010. Language learning strategy use by Colombian adult English language learners: a phenomenological study. In: Eid, A. 2012. Language learning strategy use of Saudi EFL students in an intensive English learning context. Asian Social Science, 8 (13): 115 - 127.

Pimm, D. 1987. Speaking Mathematically. London: Routledge \& Kegan Paul.

Pretorius, EJ \& DM Mampuru, 2007. Playing football without a ball: language, reading and academic performance in a high-poverty school. Journal of Research in Reading, 30 (1): 38 - 58.

South African University Vice Chancellors Association (SAUVCA), September 2003. Summary Report. The FET schools policy: The National Curriculum Statement and FETC (General) exit qualification. 
Setati, M. 2008. Access to mathematics versus access to the language of power: The struggle in multilingual mathematics classrooms. South African Journal of Education, 28: 103 - 116.

Taylor, N. 2015. Initial Teacher Education Research Project: An examination of aspects of initial teacher education curricula at five higher education institutions. Summary Report. Johannesburg: JET Education Services.

Trends in Mathematics and Science Studies (TIMSS), 2013. Assessment Frameworks. International Association for the Evaluation of Educational Achievement (IEA). TIMSS \& PIRLS International Study Centre, Lynch School of Education, Boston College, Chestnut Hill, MA.

Tshabalala, L. 2012. Exploring Language Issues in Multilingual Classrooms. Learning and Teaching Mathematics. A Journal of AMESA, 13: 22-25.

Tshuma, L. 2017. Multiple levels and aspects of language competency in English and Intermediate Phase mathematics teachers: An analysis of case of the Eastern Cape Province. Unpublished PhD Thesis. Stellenbosch: University of Stellenbosch.

\footnotetext{
ii Annual National Assessments were discontinued in 2014 due to lack of capacity to administer the assessments.

iii ABET is now called Adult Education and Training (AET).

${ }^{\text {iv }}$ A matric certificate is offered after completing the $12^{\text {th }}$ grade of the South African ordinary school system. The issuing of certificates is standardised and quality assured by Umalusi Council in conjunction with the Department of Basic Education, (DBE).

"The MRTEQ provides 'a basis for the construction of core curricula for Initial Teacher Education (ITE), as well as for Continuing Professional Development (CPD) Programmes that accredited institutions must use in order to develop programmes leading to teacher education qualifications'. The policy is based on the 2011 MRTEQ policy.
}

\section{BIOGRAPHICAL NOTES}

Dr Lindiwe Tshuma is currently a Teaching and Learning Advisor at University of the Witwatersrand and a Research Fellow at University of Stellenbosch. Previously she was an IP mathematics lecturer, a Curriculum Development Specialist and also taught Mathematics and English in various under-resourced public schools for several years.

Prof Michael le Cordeur is professor and chair of Curriculum Studies in the Education Faculty at Stellenbosch University. A language teacher by trade, he is a former high school principal and Circuit Manager of Education in Stellenbosch. A regular columnist for various media \& houses he is one of the first recipients of Stellenbosch's Media Award of Excellence (2018), and also recipient of various other awards, such as from the South African Academy and Stellenbosch University's Chancellors Award (2014). 